\title{
Trimesic Acid-Functionalized Chitosan: A Novel And Efficient Multifunctional Organocatalyst For Green Synthesis of Polyhydroquinolines And Acridinediones Under Mild Conditions
}

\author{
Rahman Beiranvand \\ Iran University of Science and Technology \\ Mohammad G. Dekamin ( $\sim$ mdekamin@iust.ac.ir) \\ Iran University of Science and Technology
}

\section{Research Article}

Keywords: Modified biopolymers, Heterogeneous organocatalysis, Biodegradable catalyst, Multicomponent reactions (MCRs), Heterocycles, Green and sustainable chemistry.

Posted Date: November 12th, 2021

DOI: https://doi.org/10.21203/rs.3.rs-1054554/v1

License: (c) (1) This work is licensed under a Creative Commons Attribution 4.0 International License. Read Full License 


\section{Abstract}

Trimesic acid-functionalized chitosan (Cs/ECH-TMA) material was prepared through a simple procedure by using chitosan (Cs), epichlorohydrin (ECH) and trimesic acid (TMA). The obtained bio-based Cs/ECHTMA material was characterized using energy-dispersive X-ray (EDX) and Fourier-transform infrared spectroscopy (FTIR) spectroscopy, field emission scanning electron microscopy (FESEM) and X-ray diffraction (XRD) analysis. The Cs/ECH-TMA material was successfully used, as a multifunctional heterogeneous and sustainable catalyst, for efficient and expeditious synthesis of medicinally important polyhydroquinoline (PHQ) and polyhydroacridinedione ( $\mathrm{PHA}$ ) scaffolds through the Hantzsch condensation in a one-pot reaction. Indeed, the heterogeneous $\mathrm{Cs} / \mathrm{ECH}-\mathrm{TMA}$ material can be considered as a synergistic multifunctional organocatalyst due to the presence of a large number of acidic active sites in its structure as well as hydrophilicity. Both PHQs and PHAs were synthesized in the presence of biodegradable heterogeneous $\mathrm{Cs} / \mathrm{ECH}$-TMA catalytic system from their corresponding substrates in EtOH under reflux conditions and high to quantitative yields. The $\mathrm{Cs} / \mathrm{ECH}-\mathrm{TMA}$ catalyst is recyclable and can be reused at least four times without significant loss of its catalytic activity.

\section{Introduction}

The use of agricultural, fishery and industrial biopolymeric byproducts have become very attractive in designing of new heterogeneous catalytic systems mainly as appropriate supports in the recent years. Indeed, these biodegradable supports are simply extracted from endless biological resources of a nontoxic nature as well as demonstrate proper synergistic catalytic activity with the active catalytic centers and biodegradability ${ }^{1-9}$. The development of new heterogeneous catalytic systems has become a major research area in recent decades due to the minimization of contamination in the organic synthesis methodology. In addition, there are several positive aspects for using of heterogeneously-catalyzed processes including simplification of procedures, assistance to decreasing trend of the waste production, easy separation and recycling of the catalysts ${ }^{10-13}$. Intersetingly, theses biomaterials are environmentally-friendly alternative supports for other materials such as diverse synthetic organic polymers ${ }^{14-17}$, metal organic frameworks (MOFs) ${ }^{18}$, graphene-oxide or its reduced form ${ }^{19-22}$, diverse

synthetic organic polymers ${ }^{14-17}$, alumina ${ }^{23}$, and silica and zeolites or their magnetic composites ${ }^{17,24-28}$ to stabilize active catalytic agents on the surface of supports to tune desired catalytic activities.

Chitosan is one of the best biopolymeric substrates which is easily obtained from natural sources and can be used for a variety of applications in numerous industrial areas ${ }^{29-31}$. It is easily derived by the random $\mathrm{N}$-deacetylation of chitin, a byproduct of the fishing industry, under alkaline conditions. Also, chitosan is a linear biopolymer with special features including hydrophilicity, crystallinity, ionic conductivity, high viscosity and nitrogen richness that make it stand out from other biopolymeric materials ${ }^{32,33}$. Due to the presence of both amino and hydroxyl groups with proper geometry on the chitosan backbone, it has a great ability to form coordination interactions and covalent bonds with a variety of metals and organic compounds, respectively. Hence, chitosan has been widely studied as an 
appropriate precursor or ingredient in various research areas ${ }^{31}$. Interestingly, chitosan has been used as a heterogeneous catalyst alone in some organic transformations ${ }^{34}$. In other cases, chitosan after postmodification with proper ligands or metallic species has also been used along with nanomaterials to proceed different catalytic reactions ${ }^{6,7,19,35-43}$. Furthermore, the non-toxic structure, presence of proper functional groups and hydrophilicity of chitosan or its derivatives make them an appropriate choice for drug delivery, anti-bacterial wound dressing materials, bioelectronics, sensors, adsorbents, hydrogels, etc $22,44-56$. Hence, designing, preparation, and exploring the applications of new chitosan-derived materials in various research fields is in high demand.

Furthermore, trimesic acid (TMA) is an organic compound with a complementary functional groups which can easily be used for various applications such as the synthesis of self-assembled dendrimers or architectures ${ }^{57,58}$, coordination polymers and metal-organic framework ${ }^{59-61}$, nonporous materials ${ }^{62}$, polyamides ${ }^{63}$, and absorbance of toxic substances and metals ${ }^{64,65}$. TMA can act as a hydrogen donor or receptor by creating a variety of resonance structures ${ }^{66}$. Due to the structural symmetry and multiplicity of the acidic agent groups of TMA, we were interested to use it by grafting to the chitosan backbone to prepare a cost-effective catalytic agent with proper catalytic efficiency.

On the other hand, literature survey shows that multi-component reactions (MCRs) are widely used to synthesize many pharmaceutical nuclei, new surfaces with proper functionalities, laser dyes or chemosensors as well as biomimetic asymmetric transfer hydrogenation and electron donors and proton sources in photoredox catalyzed processes including Hantzsch esters ${ }^{17,25,67-75}$. One of the well-known methods for synthesis of polyhydroquinolines (PHQs) and polyhydroacridinediones (PHAs), as two scaffolds containing 1,4-dihydropyridines (1,4-DHP) moiety, is the Hantzsch condensation. For example, amlodipine, felodipine, nicardipine and nifedipine which are classified as economic drugs, obtained from this method. These pharmaceticals are considered as L-type $\mathrm{Ca}^{2+}$ channels (LTCC) blockers and mainly applied for the treatment of hypertension and angina ${ }^{76}$. Therefore, due to significant and wide applications of 1,4-DHPs in different areas as well as efficiency and low cost of Hantzsch method for the synthesis of these compounds, the multicomponent reaction of 1,3-dicarbonyl compounds, aldehydes and an amine source is still considered as the first choice. Hence, different homogeneous or heterogeneous acidic and basic catalytic systems have been introduced to proceed Hantzsch condensation more efficiently. Some recent catalytic systems for promoting of PHQs and PHAs synthesis are sulfonic acid supported $\mathrm{y}-\mathrm{Fe}_{2} \mathrm{O}_{3}{ }^{77}, \mathrm{Zn}[(\mathrm{L}) \text { proline }]_{2}{ }^{78}, 3,4,5$-trifluorobenzeneboronic acid in ionic liquid ${ }^{79} \mathrm{Co}_{3} \mathrm{O}_{4}$ - CNT nanocomposites, platinum nanoparticles supported with reduced graphene oxide ${ }^{80}$, nickel containing ionic liquid based ordered nanoporous organosilica, 1,3,5-tris(2-hydroxyethyl) isocyanurate covalently functionalized MCM-41, urease enzyme ${ }^{81}$, layered double hydroxides and $\mathrm{PPh}_{3}$ 82. It is obvious that each of these catalytic systems has simultaneously their own advantages and disadvantages for catalyzing of Hantzsch's reaction. Hence, there is still much room for designing and exploring of new and more efficient catalytic systems with tailored functional groups, which address green and sustainable chemistry principles. In continuation of our interest to develop natural biopolymers 
or their modified products, as efficient catalytic systems for different organic transformation, we wish herein to report trimesic acid-functionalized chitosan (Cs/ECH-TMA) materials for efficient synthesis of $\mathrm{PHQ}$ s and PHAs in EtOH/H2O under reflux conditions (Scheme 1). Indeed, avoiding the use of toxic substances and metals in the synthesis of Cs/ECH-TMA catalyst is one of the advantages of this work. This was achieved by the use of commercially available and biodegradable chitosan polysaccharide and epichlorohydrin.

\section{Experimental Section}

\section{Reagents and apparatus}

All chemicals and reagents were purchased from Merck and Aldrich and used without further purification, except for benzaldehyde, which was used as a freshly distilled sample. Chitosan (MW =600,000800,000 Dalton) was purchased from Acros Organics and used without any modification. Melting points were determined using a digital Electrothermal 9100 capillary apparatus and are uncorrected. Fouriertransform infrared spectroscopy (FTIR) spectra were recorded, as KBr pellets, on a Shimadzu FT-IR-8400S spectrometer. ${ }^{1} \mathrm{H}$ NMR spectra $(500 \mathrm{MHz})$ were obtained using a Bruker DRX-500 Avance spectrometer. All

${ }^{1} \mathrm{H}$ NMR spectra were run in $\mathrm{CDCl}_{3}$ solution, relative to TMS (0.00 ppm), at ambient temperature. Analytical thin layer chromatography (TLC) was performed using Merck $0.2 \mathrm{~mm}$ silica gel $60 \mathrm{~F}-254 \mathrm{Al}-$ plates for monitoring of reactions. All products were characterized by spectroscopic methods (IR and ${ }^{1} \mathrm{H}$ NMR spectra) and melting points.

\section{General procedure for the preparation of heterogeneous Cs/ECH-TMA organocatalyst (1)}

In a $100 \mathrm{~mL}$ round button flask, chitosan ( $\mathrm{MW}=600,000-800,000$ Dalton, Acros Organics, $1 \mathrm{~g}$ ) was suspended in $50 \mathrm{~mL}$ of $\mathrm{EtOH} / \mathrm{H}_{2} \mathrm{O}(1: 1)$. Then, epichlorohydrin $\left(\mathrm{d}=1.183 \mathrm{~g} \cdot \mathrm{ml}^{-1}, 1 \mathrm{ml}, 12.8 \mathrm{mmol}\right)$ was added to the obtained mixture, stirred and heated under reflux conditions for $3 \mathrm{~h}$. After that, the obtained solid was filtered off and suspended in $\mathrm{EtOH}(3 \times 2 \mathrm{ml})$ for 10 min and then filtered by vacuum filtration. The solid was dried in an oven at $60^{\circ} \mathrm{C}$ for $8 \mathrm{~h}$ to afford the epichlorohydrine-grafted chitosan (Cs-ECH). In the next step, Cs-ECH (0.5 g) and triethylamine (TEA, $2 \mathrm{ml})$ were suspended in DMSO $(30 \mathrm{ml})$ and stirred for $30 \mathrm{~min}$. at room temperature. Then, trimesic acid (TMA, $2.4 \mathrm{mmol}, 0.5 \mathrm{~g}$ ) was added to the obtained mixture and stirred at $100^{\circ} \mathrm{C}$ for $4 \mathrm{~h}$. The obtained solid was filtered and washed with acetone $(3 \times 2 \mathrm{ml})$ and soaked in $\mathrm{HCl}$ solution $(1 \mathrm{M})$ for $3 \mathrm{~h}$. Then, the obtained deep cream powder was washed with deionized water $(3 \times 5 \mathrm{ml})$ and dried in oven to afford catalyst 1 .

General procedure for the synthesis of PHQ (6a-n) and PHA (7a-l) derivatives catalyzed by Cs/ECH-TMA (1) 
In a $10 \mathrm{~mL}$ round-bottom flask equipped with a magnetic stirring bar and reflux condenser, aldehyde (2a-I, $1 \mathrm{mmol})$, dimedone $(3,1 \mathrm{mmol})$ and ethyl acetoacetate $(5,1 \mathrm{mmol}), \mathrm{NH}_{4} \mathrm{OAc}(5,1.2 \mathrm{mmol})$, and $\mathrm{Cs} / \mathrm{ECH}-$ TMA (1, $10 \mathrm{mg})$ were mixed in $\mathrm{EtOH}(96 \%, 2 \mathrm{~mL})$. The reaction mixture was stirred and heated under reflux conditions for the reaction times indicated in Table 3 . The progress of the reaction was monitored by TLC. After completion of the reaction, $\mathrm{EtOH}(96 \%, 2 \mathrm{~mL})$ was added to dissolve any solid crude product 6 and remain the solid catalyst 1 insoluble. The mixture was separated by vacuum filtration, allowing the filtrate solution to cool over time to obtain the desired polyhydroquinolines (PHQs, 6) crystals. The products were finally collected by vacuum filtration, washed with $\mathrm{EtOH}(96 \%, 2 \mathrm{~mL})$ and dried at $50{ }^{\circ} \mathrm{C}$ for $1 \mathrm{~h}$. In the case of polyhydroacridinediones (PHAs, 7), aldehyde (2,1 mmol), dimedone (3, $2 \mathrm{mmol})$, $\mathrm{NH}_{4} \mathrm{OAc}(4,1.2 \mathrm{mmol})$ and $\mathrm{Cs} / \mathrm{ECH}-\mathrm{TMA}(1,10 \mathrm{mg})$ were mixed in $\mathrm{EtOH}(96 \%, 2 \mathrm{~mL})$ by following the same described procedure.

\section{Results And Discussion}

\section{Preparation of the Cs/ECH-TMA organocatalyst (1)}

The trimesic acid-functionalized chitosan (Cs/ECH-TMA) materials were simply prepared by grafting of the trimesic acid (TMA) to the chitosan (Cs) backbone using epichlorohydrin (ECH), as an applicable and inexpensive linker, under mild conditions (Scheme 1). For this purpose, several paths have been reported. However, the $\mathrm{EtOH} / \mathrm{H}_{2} \mathrm{O}$ (1:1) solvent was chosen, which demonstrated to be more efficient than chloride group other solvents ${ }^{83}$. Due to the higher reactivity of the epoxy ring of $\mathrm{ECH}$, under the reported conditions, the amine group opens the ring instead of the chlorine substitution reaction. In the next step, the aprotic and polar DMSO solvent was used in the presence of trimethylamine (TEA) organic base to activate the carboxylic acid group of TMA and completion of the chloride group substitution reaction. It should be noted that due to the existence of three acidic functional groups of trimesic acid, different ammonium carboxylate salts with triethylamine can be formd. Hence, after preparing and washing the catalyst 1 , it was soaked in dilute $\mathrm{HCl}$ solution for several hours to recover the remaining carboxylic acid functional groups of TMA moiety.

\section{Characterizion of the Cs/ECH-TMA organocatalyst (1)}

In order to investigate the surface functionalization of Cs with TMA moieties, several appropriate techniques such as Fourier transform infrared (FTIR) spectroscopy, field emission scanning electron microscopy (FESEM), thermal gravimetric analysis (TGA), energy dispersive X-ray (EDX) spectroscopy and X-ray powder diffraction (XRD) were used. Fig. 1 shows the FTIR spectra of chitosan (a), Cs/ECH (b) and Cs/ECH-TMA (c), respectively. As can be seen, the signal related to the asymmetric and symmetric stretching vibration of $\mathrm{N}-\mathrm{H}$ bond at $~ 3500$ is observed in the all spectra (a-c). Of course, the broad adsorption band at 3450-3150 $\mathrm{cm}^{-1}$ can be attributed to the stretching vibration of the hydroxyls group of both $\mathrm{Cs}$ and $\mathrm{ECH}$ linker. Furthermore, the strong absorption band at $1725 \mathrm{~cm}^{-1}$ is as assigned to the stretching vibration of carbonyl group $(\mathrm{C}=\mathrm{O})$ and confirms the presence of trimesic acid in the structure of 
Cs/ECH-TMA (1, spectrum c). On the other hand, two absorption bands near 1240 and $1370 \mathrm{~cm}^{-1}$ are related to the in-plane bending vibration of hydroxyl groups, respectively ${ }^{84}$.

The presence of chlorine element in the EDX analysis of Cs/ECH (a) confirms that the first step in the preparation of the catalyst 1 was successfully performed. Subsequent elimination of the chlorine element in the EDX analysis of Cs/ECH-TMA (b) is a clear indication of its substitution with the carboxylic acid functional groups of TMA by a covalent binding to the chitosan backbone (Fig. 2).

Field emission scanning electron microscopy (FESEM) images (Fig. 3) show the morphology of Cs/ECHTMA material (c-d) compared to the commercial chitosan (a-b). The surface of the commercial chitosan is almost smooth (3a-b) and free of cross-linked groups including ECH and TMA. However, additional particles have spread across the surface of the Cs support and demonstrating its uniform functionalization by the TMA units grafted by the ECH linker (3c-d). The bulk of these particles is probably related to hydrogen bondings and the self-assembly of TMA moieties.

The XRD spectra of the commercial chitosan and Cs/ECH-TMA material was also studied (Fig. 4). The characteristic peaks at about $2 \Theta=10^{\circ}$ and $20^{\circ}$ are related to the structure of pristine chitosan (4a). After grafting of TMA on the chitosan backbone, its crystalline structure changes and new signals appear at $21.2^{\circ}, 23.0^{\circ}, 28.3^{\circ}, 30.7^{\circ}$ and $41.8^{\circ}(\mathbf{4 b})$. Furthermore, observation of wide peaks in the spectrum (4b) indicates lower crystallinity of the catalyst 1 than the pristine chitosan which can be attributed to the linkage of TMA on the surface of chitosan.

\section{Investigation of the catalytic activity of Cs/ECH-TMA for synthesis of PHQ and PHA derivatives}

In order to evaluate the catalytic activity of $\mathrm{Cs} / \mathrm{ECH}-\mathrm{TMA}$ and achieve the desired conditions for the synthesis of polyhydroquinolines (PHQs) and polyhydroacridinediones (PHAs), different factors including solvent, temperature and time in the presence of the variable amount of Cs/ECH-TMA catalyst 1 were examined (Table 1). For this purpose, the four component condensation of ethyl acetoacetate $(3,1.0$ $\mathrm{mmol})$, dimedone $(4,1.0 \mathrm{mmol})$, 4-chlorobenzaldehyde $(2 \mathrm{a}, 1.0 \mathrm{mmol})$ and ammonium acetate $(5,1.2$ $\mathrm{mmol}$ ), was investigated as the model reaction. The results have been summarized in Tables 1 and $\mathbf{2}$.

Initially, the reaction was performed without any catalyst, and the reaction efficiency for the synthesis of desired product, 4-(4-chlorophenyl)-2,7,7-trimethyl-5-oxo-5,6,7,8-tetrahydroquinoline-3-carboxylate (6a), was below $30 \%$ after three hours (entry 1). Then, commercial chitosan was used, as a catalyst, in the model reaction which did not afford high yield of the desired product $\mathbf{6 a}$ (entry 2 ). To determine the optimized conditions, different amounts of catalyst loading were used (entries 3-6). The best conditions are given in entry 5 of Table 1 . The results clearly confirm the high impact of Cs/ECH-TMA to proceed the model reaction. Investigation of the solvent effect showed that polar protic solvents (entries 5, 10 and 18) demonstrate higher efficiency than polar aprotic solvents (entries 13-16). On the other hand, solvent-free conditions afforded moderate yields of the desired products at both 60 and $110^{\circ} \mathrm{C}$ (entries 11 and 17). 
To show the general scope of the reaction, different aromatic aldehydes bearing electron-withdrawing or electron-donating substituents $2 a-n$ were investigated under optimized conditions (10 mg Cs/ECH-TMA loading in $\mathrm{EtOH}$ under reflux conditions). The results have been summarized in Table 2. Indeed, the catalyst 1 demonstrated a high activity for the synthesis of corresponding PHQa and the desired products were obtained in high to excellent yields and short reaction time. As shown in the Table 2, aldehydes with electron-withdrawing groups on the aromatic ring (entries 1-2, 6, 8 and 12) produced higher yields of the desired products in shorter reaction times compared to those ones bearing electron-donating groups. This can be attributed to higher susceptibility of the carbonyl group in aldehydes with electron-withdrawing groups toward nucleophilic addition of the enolic components of Hantzsch reaction in order to form the corresponding Knoevenagle intermediates. However, aldehydes bearing nitro groups (entries 3 and 5) afforded lower yields of their corresponding PHQ derivatives compared to other electron-withdrawing groups. This behavior is relevant to simultaneous formation of the corresponding imines of nitro derivatives by reaction with $\mathrm{NH}_{3}$ demonstrating lower activity as well as redox

disproportionation of their PHQs ${ }^{6}$. In general, other aldehydes have been well activated by the catalyst 1 and yields of desired products under optimized conditions were shown to be high to excellent.

In addition, the catalyst activity under optimized conditions was investigated for the production of 3,3,6,6tetramethyl-3,4,6,7,9,10-hexahydro-2H,5H-1,8-acridinedione derivatives (PHAs, 7a-l) from pseudo-fourcomponent condensation of dimedone (4), aromatic aldehydes $2 \mathrm{a}-\mathrm{I}$ and ammonium acetate (5). As shown in Table 3, it takes less time to produce PHA derivatives 7 than PHQs ones 6 under the same conditions. Aldehydes with electron-withdrawing groups on the aromatic ring, except nitro groups (entries $1-2,6,8$ and 12), are more reactive than aldehydes bearing electron-releasing groups in the same way.

According to the obtained results, the mechanism presented in Scheme 2 can be proposed for the synthesis of PHQs (6a-n) and (5a-l) catalyzed by Cs/ECH-TMA (1). In the first step, acidic protons of the trimesic acid moiety of catalyst 1 cause activation of the carbonyl functional group of aldehydes 2 to react with the enolic form of dimedone ( $\mathbf{3}^{\prime}$ ) and affording the corresponding Knoevenagel intermediates (II). This a, $\beta$-unsaturated dicarbonyl is then activated by Cs/ECH-TMA (1) and react with the enol form of $\beta$-dicarbonyls ( $\mathbf{3}^{\prime}$ or $\mathbf{4}^{\prime}$ ) to form the Michael adduct intermediate (IV). In the next step, the intermediate (IV) react on its ketone unctional group with the ammonia source (5) and forms imine intermediate (V). After tautomerization of the imine intermediate $(\mathrm{V})$ and its conversion to the corresponding enamine intermediate $(\mathbf{V I})$, the intramolecular reaction between enamine $(\mathrm{VI})$ and remaining ketone functional group leads to ring closure. Eventually, by elimination of the third $\mathrm{H}_{2} \mathrm{O}$ molecule, $\mathrm{PHQ}$ (6) or PHA (7) derivatives are produced. Furthermore, due to the presence of a large numbers of hydroxyl groups in the chitosan backbone and the ECH linker of the Cs/ECH-TMA catalyst 1, water molecules can be adsorbed on its surface to promote the Hantzsch condensations smoothly. Moreover, this hydroxyl groups contribute to more activation of carbonyl groups by development hydrogen bonding. Hence, the heterogeneous $\mathrm{Cs} / \mathrm{ECH}$-TMA materials can be considered as a synergistic multifunctional organocatalyst due to the presence of a large number of acidic active sites in its structure as well as hydrophilicity. 
Due to the importance of heterogeneous catalyst recycling for industrial applications, we investigated this important aspect of the $\mathrm{Cs} / \mathrm{ECH}$-TMA catalyst properties. Therefore, after completion the reaction, the $\mathrm{Cs} / \mathrm{ECH}-\mathrm{TMA}$ material was separated from the reaction medium and washed three times with acetone solvent. Then, the separated catayst was dried in an oven at $60^{\circ} \mathrm{C}$ for $6 \mathrm{~h}$ to be used for the next run. As shown in Fig. 5, the activity of catalyst for synthesis of desired products was still significant after five uses.

Finally, in order to further clarify the high efficiency of Cs/ECH-TMA organocatalyst (1) and the merits of the present protocol for the synthesis of polyhydroquinolines and acridinediones, several previously reported methods are listed in Table $\mathbf{4}$ for comparison. As can be seen, the present work is indeed preferable to several of the others in terms of the use of biodegradable catalyst, isolated yields, short reaction time, elimination of toxic transition metals and solvents, and use of low catalyst loading to accelerate synthesis of PHQs and PHAs.

\section{Conclusions}

In summary, novel trimesic acid-functionalized chitosan (Cs/ECH-TMA) materials were prepared through a simple procedure and properly characterized. The $\mathrm{Cs} / \mathrm{ECH}$-TMA material was used, as a reusable, and multifunctional organocatalyst, for the multicomponent reactions for synthesis of polyhydroquinolines (PHQs) and polyhydroacridinediones (PHAs) under mild and sustainable conditions. The heterogeneous $\mathrm{Cs} / \mathrm{ECH}-\mathrm{TMA}$ material was demonstrated to act as synergistic multifunctional organocatalyst due to the presence of a large number of acidic active sites in its structure as well as hydrophilicity. Indeed, the use of a metal-free and low loading catalyst with facile separation from the reaction mixture and its reusability as well as commercially available biomaterial precursor and short reaction time in a green solvent are important advantages of this new methodology.

\section{Declarations}

\section{Acknowledgements}

We are grateful for the financial support from The Research Council of Iran University of Science and Technology (IUST), Tehran, Iran (Grant No: 160/19810). The partial financial support of The Iran Nanotechnology Initiative Council (INIC) is also gratefully acknowledged.

\section{References}

1 Chen, Y., Hung, S.-T., Chou, E. \& Wu, H.-S. Review of polyhydroxyalkanoates materials and other biopolymers for medical applications. Mini-Reviews in Organic Chemistry 15, 105-121 (2018).

2 Baran, T. \& Menteş, A. Construction of new biopolymer (chitosan)-based pincer-type Pd (II) complex and its catalytic application in Suzuki cross coupling reactions. Journal of Molecular Structure 1134, 591598 (2017). 
3 Kosera, V. S., Cruz, T. M., Chaves, E. S. \& Tiburtius, E. R. Triclosan degradation by heterogeneous photocatalysis using $\mathrm{ZnO}$ immobilized in biopolymer as catalyst. Journal of Photochemistry and Photobiology A: Chemistry 344, 184-191 (2017).

4 Cui, W. et al. Mo2C Nanoparticles Decorated Graphitic Carbon Sheets: Biopolymer-Derived Solid-State Synthesis and Application as an Efficient Electrocatalyst for Hydrogen Generation. ACS Catalysis 4, 26582661, doi:10.1021/cs5005294 (2014).

5 Guan, Q. et al. Reactive Metal-Biopolymer Interactions for Semihydrogenation of Acetylene. ACS Catalysis 9, 11146-11152, doi:10.1021/acscatal.9b04042 (2019).

6 Dekamin, M. G., Kazemi, E., Karimi, Z., Mohammadalipoor, M. \& Naimi-Jamal, M. R. Chitosan: An efficient biomacromolecule support for synergic catalyzing of Hantzsch esters by CuSO4. International journal of biological macromolecules 93, 767-774 (2016).

7 Alirezvani, Z., Dekamin, M. G. \& Valiey, E. Cu (II) and magnetite nanoparticles decorated melaminefunctionalized chitosan: A synergistic multifunctional catalyst for sustainable cascade oxidation of benzyl alcohols/Knoevenagel condensation. Scientific reports 9, 1-12 (2019).

8 Dekamin, M. G. et al. Alginic acid: a highly efficient renewable and heterogeneous biopolymeric catalyst for one-pot synthesis of the Hantzsch 1,4-dihydropyridines. RSC Advances 4, 56658-56664, doi:10.1039/C4RA11801D (2014).

9 Shen, C., Xu, J., Yu, W. \& Zhang, P. A highly active and easily recoverable chitosan@ copper catalyst for the $C-S$ coupling and its application in the synthesis of zolimidine. Green Chemistry 16, 3007-3012 (2014).

10 Lanzafame, P., Perathoner, S., Centi, G., Gross, S. \& Hensen, E. Grand challenges for catalysis in the Science and Technology Roadmap on Catalysis for Europe: moving ahead for a sustainable future. Catalysis Science \& Technology 7, 5182-5194 (2017).

11 Lucarelli, C. \& Vaccari, A. Examples of heterogeneous catalytic processes for fine chemistry. Green chemistry 13, 1941-1949 (2011).

12 Liang, J., Liang, Z., Zou, R. \& Zhao, Y. Heterogeneous catalysis in zeolites, mesoporous silica, and metal-organic frameworks. Advanced Materials 29, 1701139 (2017).

13 Wacławek, S., Padil, V. V. \& Černík, M. Major advances and challenges in heterogeneous catalysis for environmental applications: a review. Ecological Chemistry and Engineering S 25, 9-34 (2018).

14 Kaur, P., Hupp, J. T. \& Nguyen, S. T. Porous organic polymers in catalysis: opportunities and challenges. ACS Catalysis 1, 819-835 (2011). 
15 Lu, J. \& Toy, P. H. Organic polymer supports for synthesis and for reagent and catalyst immobilization. Chemical reviews 109, 815-838 (2009).

16 Alirezvani, Z., Dekamin, M. G., Davoodi, F. \& Valiey, E. Melamine-Functionalized Chitosan: A New BioBased Reusable Bifunctional Organocatalyst for the Synthesis of Cyanocinnamonitrile Intermediates and Densely Functionalized Nicotinonitrile Derivatives. 3, 10450-10463, doi:10.1002/slct.201802010 (2018).

17 Karami, S., Dekamin, M. G., Valiey, E. \& Shakib, P. DABA MNPs: a new and efficient magnetic bifunctional nanocatalyst for the green synthesis of biologically active pyrano[2,3-c]pyrazole and benzylpyrazolyl coumarin derivatives. New Journal of Chemistry 44, 13952-13961, doi:10.1039/D0NJ02666B (2020).

18 Chen, Y.-Z., Zhang, R., Jiao, L. \& Jiang, H.-L. Metal-organic framework-derived porous materials for catalysis. Coordination Chemistry Reviews 362, 1-23 (2018).

19 Zheng, X., Zhao, J., Xu, M. \& Zeng, M. Preparation of porous chitosan/reduced graphene oxide microspheres supported Pd nanoparticles catalysts for Heck coupling reactions. Carbohydrate Polymers 230, 115583, doi:https://doi.org/10.1016/j.carbpol.2019.115583 (2020).

20 Shan, C. et al. Graphene oxide enhanced polyacrylamide-alginate aerogels catalysts. Carbohydrate Polymers 203, 19-25, doi:https://doi.org/10.1016/j.carbpol.2018.09.024 (2019).

21 Hasanzadeh Banakar, S., Dekamin, M. G. \& Yaghoubi, A. Selective and highly efficient synthesis of xanthenedione or tetraketone derivatives catalyzed by $\mathrm{ZnO}$ nanorod-decorated graphene oxide. New Journal of Chemistry 42, 14246-14262, doi:10.1039/C8NJ01053F (2018).

22 Adeel, M., Bilal, M., Rasheed, T., Sharma, A. \& Iqbal, H. M. N. Graphene and graphene oxide: Functionalization and nano-bio-catalytic system for enzyme immobilization and biotechnological perspective. International Journal of Biological Macromolecules 120, 1430-1440, doi:https://doi.org/10.1016/j.ijbiomac.2018.09.144 (2018).

23 Pines, H. \& Manassen, J. in Advances in catalysis Vol. 16 49-93 (Elsevier, 1966).

24 Bhatia, S. Zeolite catalysts: principles and applications. (CRC press, 1989).

25 Alirezvani, Z., Dekamin, M. G. \& Valiey, E. New Hydrogen-Bond-Enriched 1,3,5-Tris(2-hydroxyethyl) Isocyanurate Covalently Functionalized MCM-41: An Efficient and Recoverable Hybrid Catalyst for Convenient Synthesis of Acridinedione Derivatives. ACS Omega 4, 20618-20633, doi:10.1021/acsomega.9b02755 (2019).

26 Akbari, A., Dekamin, M. G., Yaghoubi, A. \& Naimi-Jamal, M. R. Novel magnetic propylsulfonic acidanchored isocyanurate-based periodic mesoporous organosilica (Iron oxide@PMO-ICS-PrSO3H) as a highly efficient and reusable nanoreactor for the sustainable synthesis of imidazopyrimidine derivatives. Scientific Reports 10, 10646, doi:10.1038/s41598-020-67592-4 (2020). 
27 Zebardasti, A., Dekamin, M. G. \& Doustkhah, E. The Isocyanurate-Carbamate-Bridged Hybrid Mesoporous Organosilica: An Exceptional Anchor for Pd Nanoparticles and a Unique Catalyst for Nitroaromatics Reduction. Catalysts 11, 621 (2021).

28 Zebardasti, A., Dekamin, M. G., Doustkhah, E. \& Assadi, M. H. N. Carbamate-Isocyanurate-Bridged Periodic Mesoporous Organosilica for van der Waals CO2 Capture. Inorganic Chemistry 59, 11223-11227, doi:10.1021/acs.inorgchem.0c01449 (2020).

29 Antony, R., Arun, T. \& Manickam, S. T. D. A review on applications of chitosan-based Schiff bases. International journal of biological macromolecules 129, 615-633 (2019).

30 Islam, S., Bhuiyan, M. R. \& Islam, M. Chitin and chitosan: structure, properties and applications in biomedical engineering. Journal of Polymers and the Environment 25, 854-866 (2017).

31 Rinaudo, M. Chitin and chitosan: properties and applications. Progress in polymer science $\mathbf{3 1}, \mathbf{6 0 3 -}$ 632 (2006).

32 Yuan, Y., Chesnutt, B. M., Haggard, W. O. \& Bumgardner, J. D. Deacetylation of chitosan: material characterization and in vitro evaluation via albumin adsorption and pre-osteoblastic cell cultures. Materials 4, 1399-1416 (2011).

33 Zargar, V., Asghari, M. \& Dashti, A. A review on chitin and chitosan polymers: structure, chemistry, solubility, derivatives, and applications. ChemBioEng Reviews 2, 204-226 (2015).

34 Dekamin, M. G., Azimoshan, M. \& Ramezani, L. Chitosan: a highly efficient renewable and recoverable bio-polymer catalyst for the expeditious synthesis of a-amino nitriles and imines under mild conditions. Green Chemistry 15, 811-820, doi:10.1039/C3GC36901C (2013).

35 El Kadib, A. Chitosan as a sustainable organocatalyst: a concise overview. ChemSusChem 8, 217-244 (2015).

36 Macquarrie, D. J. \& Hardy, J. J. Applications of functionalized chitosan in catalysis. Industrial \& engineering chemistry research 44, 8499-8520 (2005).

37 Valiey, E., Dekamin, M. G. \& Alirezvani, Z. Melamine-modified chitosan materials: An efficient and recyclable bifunctional organocatalyst for green synthesis of densely functionalized bioactive dihydropyrano[2,3-c]pyrazole and benzylpyrazolyl coumarin derivatives. International Journal of Biological Macromolecules 129, 407-421, doi:https://doi.org/10.1016/j.ijbiomac.2019.01.027 (2019).

38 Khan, K. \& Siddiqui, Z. N. An Efficient Synthesis of Tri- and Tetrasubstituted Imidazoles from Benzils Using Functionalized Chitosan as Biodegradable Solid Acid Catalyst. Industrial \& Engineering Chemistry Research 54, 6611-6618, doi:10.1021/acs.iecr.5b00511 (2015). 
39 Ahmed, N. \& Siddiqui, Z. N. Cerium Supported Chitosan as an Efficient and Recyclable Heterogeneous Catalyst for Sustainable Synthesis of Spiropiperidine Derivatives. ACS Sustainable Chemistry \& Engineering 3, 1701-1707, doi:10.1021/acssuschemeng.5b00223 (2015).

40 Zhao, Z.-S., Zhang, Y., Fang, T., Han, Z.-B. \& Liang, F.-S. Chitosan-Coated Metal-Organic-Framework Nanoparticles as Catalysts for Tandem Deacetalization-Knoevenagel Condensation Reactions. ACS Applied Nano Materials 3, 6316-6320, doi:10.1021/acsanm.0c01486 (2020).

41 Tang, Z. et al. Cobalt-Tetraamide-Phthalocyanine Immobilized on Fe304/Chitosan Microspheres as an Efficient Catalyst for Baeyer-Villiger Oxidation. ACS Omega 5, 10451-10458, doi:10.1021/acsomega.0c00443 (2020).

42 Jirawutthiwongchai, J., Krause, A., Draeger, G. \& Chirachanchai, S. Chitosan-Oxanorbornadiene: A Convenient Chitosan Derivative for Click Chemistry without Metal Catalyst Problem. ACS Macro Letters 2, 177-180, doi:10.1021/mz400006j (2013).

43 Vincent, T. \& Guibal, E. Chitosan-Supported Palladium Catalyst. 5. Nitrophenol Degradation Using Palladium Supported on Hollow Chitosan Fibers. Environmental Science \& Technology 38, 4233-4240, doi:10.1021/es034862m (2004).

44 Rebelo, R., Fernandes, M. \& Fangueiro, R. Biopolymers in medical implants: a brief review. Procedia engineering 200, 236-243 (2017).

45 García, M. C. et al. Bioadhesive and biocompatible films as wound dressing materials based on a novel dendronized chitosan loaded with ciprofloxacin. Carbohydrate polymers 175, 75-86 (2017).

46 Singh et al. Preparation and properties of highly soluble chitosan-I-glutamic acid aerogel derivative. Carbohydrate Polymers 76, 188-195 (2009).

47 Primo, A., Forneli, A., Corma, A. \& García, H. From Biomass Wastes to Highly Efficient CO2 Adsorbents: Graphitisation of Chitosan and Alginate Biopolymers. ChemSusChem 5, 2207-2214, doi:https://doi.org/10.1002/cssc.201200366 (2012).

48 Wang, C., Yokota, T. \& Someya, T. Natural Biopolymer-Based Biocompatible Conductors for Stretchable Bioelectronics. Chemical Reviews 121, 2109-2146, doi:10.1021/acs.chemrev.0c00897 (2021).

49 Cui, L. et al. pH-Triggered Charge-Reversal Mesoporous Silica Nanoparticles Stabilized by Chitosan Oligosaccharide/Carboxymethyl Chitosan Hybrids for Effective Intracellular Delivery of Doxorubicin. ACS Applied Bio Materials 2, 1907-1919, doi:10.1021/acsabm.8b00830 (2019).

50 Wang, R. et al. Forward Wound Closure with Regenerated Silk Fibroin and Polylysine-Modified Chitosan Composite Bioadhesives as Dressings. ACS Applied Bio Materials 3, 7941-7951, doi:10.1021/acsabm.0c01064 (2020). 
51 Cui, C., Shao, C., Meng, L. \& Yang, J. High-Strength, Self-Adhesive, and Strain-Sensitive Chitosan/Poly (acrylic acid) Double-Network Nanocomposite Hydrogels Fabricated by Salt-Soaking Strategy for Flexible Sensors. ACS applied materials \& interfaces 11, 39228-39237 (2019).

52 Morikawa, K., Masubuchi, Y., Shchipunov, Y. \& Zinchenko, A. DNA-Chitosan Hydrogels: Formation, Properties, and Functionalization with Catalytic Nanoparticles. ACS Applied Bio Materials 4, 1823-1832, doi:10.1021/acsabm.0c01533 (2021).

53 Essawy, H. A., Ghazy, M. B., Abd El-Hai, F. \& Mohamed, M. F. Superabsorbent hydrogels via graft polymerization of acrylic acid from chitosan-cellulose hybrid and their potential in controlled release of soil nutrients. International journal of biological macromolecules 89, 144-151 (2016).

54 Hassan, M. A., Omer, A. M., Abbas, E., Baset, W. M. \& Tamer, T. M. Preparation, physicochemical characterization and antimicrobial activities of novel two phenolic chitosan Schiff base derivatives. Scientific reports 8, 1-14 (2018).

$55 \mathrm{Nie}, \mathrm{J}$. et al. Orientation in multi-layer chitosan hydrogel: morphology, mechanism and design principle. Scientific reports 5, 1-7 (2015).

$56 \mathrm{Babu}, \mathrm{A}$. et al. Chemodrug delivery using integrin-targeted PLGA-Chitosan nanoparticle for lung cancer therapy. Scientific reports 7, 1-17 (2017).

57 Nath, K. G. et al. Rational Modulation of the Periodicity in Linear Hydrogen-Bonded Assemblies of Trimesic Acid on Surfaces. Journal of the American Chemical Society 128, 4212-4213, doi:10.1021/ja0602896 (2006).

58 Wendland, M. S. \& Zimmerman, S. C. Synthesis of Cored Dendrimers. Journal of the American Chemical Society 121, 1389-1390, doi:10.1021/ja983097m (1999).

59 Song, J. et al. A Multiunit Catalyst with Synergistic Stability and Reactivity: A Polyoxometalate-Metal Organic Framework for Aerobic Decontamination. Journal of the American Chemical Society 133, 1683916846, doi:10.1021/ja203695h (2011).

60 Cheng, D., Khan, M. A. \& Houser, R. P. Coordination Polymers Composed of Copper(II), Trimesic Acid, and Imidazole: 3D Architecture Stabilized by Hydrogen Bonding. Inorganic Chemistry 40, 6858-6859, doi:10.1021/ic015609v (2001).

61 Chui, S. S.-Y., Lo, S. M.-F., Charmant, J. P., Orpen, A. G. \& Williams, I. D. A chemically functionalizable nanoporous material [Cu3 (TMA) 2 (H2O) 3] n. Science 283, 1148-1150 (1999).

62 Dmitriev, A., Lin, N., Weckesser, J., Barth, J. \& Kern, K. Supramolecular assemblies of trimesic acid on a $\mathrm{Cu}$ (100) surface. The Journal of Physical Chemistry B 106, 6907-6912 (2002). 
63 Jikei, M. et al. Synthesis of hyperbranched aromatic polyamide from aromatic diamines and trimesic acid. Macromolecules 32, 2061-2064 (1999).

64 Herbstein, F., Kapon, M. \& Reisner, G. Catenated and non-catenated inclusion complexes of trimesic acid. Journal of inclusion phenomena 5, 211-214 (1987).

$65 \mathrm{Li}, \mathrm{H}$. et al. Efficient removal of uranium using a melamine/trimesic acid-modified hydrothermal carbon-based supramolecular organic framework. Journal of colloid and interface science 544, 14-24 (2019).

66 Nikooei, N., Dekamin, M. G. \& Valiey, E. Benzene-1,3,5-tricarboxylic acid-functionalized MCM-41 as a novel and recoverable hybrid catalyst for expeditious and efficient synthesis of 2,3-dihydroquinazolin4(1H)-ones via one-pot three-component reaction. Research on Chemical Intermediates 46, 3891-3909, doi:10.1007/s11164-020-04179-8 (2020).

67 Domling, A., Wang, W. \& Wang, K. Chemistry and biology of multicomponent reactions. Chemical reviews 112, 3083-3135 (2012).

68 Müller, T. J. J. in Functional Organic Materials 179-223 (2006).

69 Afshari, R. \& Shaabani, A. Materials Functionalization with Multicomponent Reactions: State of the Art. ACS Combinatorial Science 20, 499-528, doi:10.1021/acscombsci.8b00072 (2018).

70 Rathee, G., Kohli, S., Singh, N., Awasthi, A. \& Chandra, R. Calcined Layered Double Hydroxides: Catalysts for Xanthene, 1,4-Dihydropyridine, and Polyhydroquinoline Derivative Synthesis. ACS Omega 5, 15673-15680, doi:10.1021/acsomega.0c01901 (2020).

71 Chen, Q.-A. et al. Biomimetic Asymmetric Hydrogenation: In Situ Regenerable Hantzsch Esters for Asymmetric Hydrogenation of Benzoxazinones. Journal of the American Chemical Society 133, 1643216435, doi:10.1021/ja208073w (2011).

72 Wang, P.-Z., Chen, J.-R. \& Xiao, W.-J. Hantzsch esters: an emerging versatile class of reagents in photoredox catalyzed organic synthesis. Organic \& Biomolecular Chemistry 17, 6936-6951, doi:10.1039/C9OB01289C (2019).

73 You, S.-L. Recent Developments in Asymmetric Transfer Hydrogenation with Hantzsch Esters: A Biomimetic Approach. Chemistry - An Asian Journal 2, 820-827, doi:https://doi.org/10.1002/asia.200700081 (2007).

74 Etivand, N., Khalafy, J. \& Dekamin, M. G. Fast and Efficient Green Procedure for the Synthesis of Benzo[5,6]chromene Derivatives and Their Sulfur Analogues in Water by Organocatalyst Potassium Phthalimide-N-oxyl. Synthesis 52, 1707-1718 (2020). 
75 Dekamin, M. G., Eslami, M. \& Maleki, A. Potassium phthalimide-N-oxyl: a novel, efficient, and simple organocatalyst for the one-pot three-component synthesis of various 2-amino-4H-chromene derivatives in water. Tetrahedron 69, 1074-1085, doi:https://doi.org/10.1016/j.tet.2012.11.068 (2013).

76 Dekamin, M. G. et al. Alginic acid: A mild and renewable bifunctional heterogeneous biopolymeric organocatalyst for efficient and facile synthesis of polyhydroquinolines. International journal of biological macromolecules 108, 1273-1280 (2018).

77 Koukabi, N. et al. A Magnetic Particle-Supported Sulfonic Acid Catalyst: Tuning Catalytic Activity between Homogeneous and Heterogeneous Catalysis. Advanced Synthesis \& Catalysis 354, 2001-2008 (2012).

78 Sivamurugan, V., Kumar, R. S., Palanichamy, M. \& Murugesan, V. Synthesis of hantzsch 1, 4 dihydropyridines under solvent-free condition using zn $[(L)$ proline] 2 as lewis acid catalyst. Journal of heterocyclic chemistry 42, 969-974 (2005).

79 Sridhar, R. \& Perumal, P. T. A new protocol to synthesize 1, 4-dihydropyridines by using 3, 4, 5trifluorobenzeneboronic acid as a catalyst in ionic liquid: synthesis of novel 4-(3-carboxyl-1H-pyrazol-4yl)-1, 4-dihydropyridines. Tetrahedron 61, 2465-2470 (2005).

80 Aday, B. et al. One-pot, efficient and green synthesis of acridinedione derivatives using highly monodisperse platinum nanoparticles supported with reduced graphene oxide. New Journal of Chemistry 40, 748-754, doi:10.1039/C5NJ02098K (2016).

81 Zhu, G. \& Li, Y. Urease: a highly efficient biocatalyst for synthesis of polyhydroquinolines and polyhydroacridines from the ammonia formed in situ. Molecular Diversity, doi:10.1007/s11030-02010109-y (2020).

82 Debache, A. et al. An efficient one-step synthesis of 1, 4-dihydropyridines via a triphenylphosphinecatalyzed three-component Hantzsch reaction under mild conditions. Tetrahedron Letters 50, 5248-5250 (2009).

83 Galhoum, A. A. et al. Dy (III) recovery from dilute solutions using magnetic-chitosan nano-based particles grafted with amino acids. Journal of Materials Science 50, 2832-2848 (2015).

84 Zheng, C., Ren, H., Cui, Z., Chen, F. \& Hong, G. Synthesis and characterization of nano-scale Terbium (III)-trimesic acid (TMA)-1, 10-phenanthroline (phen) luminescent complex. Journal of alloys and compounds 477, 333-336 (2009).

85 Dondoni, A., Massi, A., Minghini, E. \& Bertolasi, V. Multicomponent Hantzsch cyclocondensation as a route to highly functionalized 2-and 4-dihydropyridylalanines, 2-and 4-pyridylalanines, and their $\mathrm{N}$-oxides: preparation via a polymer-assisted solution-phase approach. Tetrahedron 60, 2311-2326 (2004). 
86 Nasr-Esfahani, M., Hoseini, S. J., Montazerozohori, M., Mehrabi, R. \& Nasrabadi, H. Magnetic Fe304 nanoparticles: efficient and recoverable nanocatalyst for the synthesis of polyhydroquinolines and Hantzsch 1, 4-dihydropyridines under solvent-free conditions. Journal of Molecular Catalysis A: Chemical 382, 99-105 (2014).

87 Maheswara, M., Siddaiah, V., Damu, G. L. V. \& Rao, C. V. An efficient one-pot synthesis of polyhydroquinoline derivatives via Hantzsch condensation using a heterogeneous catalyst under solventfree conditions. Arkivoc 2, 201-206 (2006).

88 Salehi, H. \& Guo, Q. X. Synthesis of Substituted 1, 4-Dihydropyridines in Water Using Phase-Transfer Catalyst Under Microwave Irradiation. Synthetic communications 34, 4349-4357 (2004).

89 Breitenbucher, J. G. \& Figliozzi, G. Solid-phase synthesis of 4-aryl-1, 4-dihydropyridines via the Hantzsch three component condensation. Tetrahedron Letters 41, 4311-4315 (2000).

90 Ko, S., Sastry, M., Lin, C. \& Yao, C.-F. Molecular iodine-catalyzed one-pot synthesis of 4-substituted-1, 4dihydropyridine derivatives via Hantzsch reaction. Tetrahedron Letters 46, 5771-5774 (2005).

91 Kumar, S., Sharma, P., Kapoor, K. K. \& Hundal, M. S. An efficient, catalyst-and solvent-free, fourcomponent, and one-pot synthesis of polyhydroquinolines on grinding. Tetrahedron 64, 536-542 (2008).

92 Loev, B. \& Snader, K. M. The Hantzsch reaction. I. Oxidative dealkylation of certain dihydropyridines. The Journal of Organic Chemistry 30, 1914-1916 (1965).

93 Donelson, J. L., Gibbs, R. A. \& De, S. K. An efficient one-pot synthesis of polyhydroquinoline derivatives through the Hantzsch four component condensation. Journal of Molecular Catalysis A: Chemical 256, 309-311 (2006).

94 Stankevich, E., Grinshtein, E. \& Dubur, G. Y. Structures of the products of the reaction of $\beta$ aminovinylcarbonyl compounds, a $\beta$-diketone, and an aldehyde. Chemistry of Heterocyclic Compounds 11, 196-198 (1975).

95 Zolfigol, M. A., Karimi, F., Yarie, M. \& Torabi, M. Catalytic application of sulfonic acid-functionalized titana-coated magnetic nanoparticles for the preparation of 1, 8-dioxodecahydroacridines and 2, 4, 6triarylpyridines via anomeric-based oxidation. Applied Organometallic Chemistry 32, e4063 (2018).

96 Rostamizadeh, S., Amirahmadi, A., Shadjou, N. \& Amani, A. M. MCM-41-SO3H as a nanoreactor for the one-pot, solvent-free synthesis of 1, 8-dioxo-9-aryl decahydroacridines. Journal of Heterocyclic Chemistry 49, 111-115 (2012).

97 Yü, S.-J., Wu, S., Zhao, X.-M. \& Lü, C.-W. Green and efficient synthesis of acridine-1, 8-diones and hexahydroquinolines via a KH 2 PO 4 catalyzed Hantzsch-type reaction in aqueous ethanol. Research on Chemical Intermediates 43, 3121-3130 (2017). 
98 Jin, T.-S., Zhang, J.-S., Guo, T.-T., Wang, A.-Q. \& Li, T.-S. One-pot clean synthesis of 1, 8-dioxodecahydroacridines catalyzed by p-dodecylbenezenesulfonic acid in aqueous media. Synthesis 2004, 2001-2005 (2004).

99 Fan, X., Li, Y., Zhang, X., Qu, G. \& Wang, J. An efficient and green preparation of 9-arylacridine-1, 8dione derivatives. Heteroatom Chemistry: An International Journal of Main Group Elements 18, 786-790 (2007).

100 Zhu, A., Liu, R., Du, C. \& Li, L. Betainium-based ionic liquids catalyzed multicomponent Hantzsch reactions for the efficient synthesis of acridinediones. RSC advances 7, 6679-6684 (2017).

101 Patil, D. et al. Novel Brønsted Acidic lonic Liquid ([CMIM][CF 3 COO]) Prompted Multicomponent Hantzsch Reaction for the Eco-Friendly Synthesis of Acridinediones: An Efficient and Recyclable Catalyst. Catalysis letters 144, 949-958 (2014).

102 Ziarani, G. M., Badiei, A., Hassanzadeh, M. \& Mousavi, S. Synthesis of 1, 8-dioxo-decahydroacridine derivatives using sulfonic acid functionalized silica (SiO2-Pr-SO3H) under solvent free conditions. Arabian Journal of Chemistry 7, 335-339 (2014).

103 Wang, G.-W., Xia, J.-J., Miao, C.-B. \& Wu, X.-L. Environmentally friendly and efficient synthesis of various 1, 4-dihydropyridines in pure water. Bulletin of the Chemical Society of Japan 79, 454-459 (2006).

104 Tiwari, K. N., Uttam, M. R., Kumari, P., Vatsa, P. \& Prabhakaran, S. Efficient synthesis of acridinediones in aqueous media. Synthetic Communications 47, 1013-1019 (2017).

105 Zarnegar, Z., Safari, J. \& Mansouri-Kafroudi, Z. Environmentally benign synthesis of polyhydroquinolines by Co304-CNT as an efficient heterogeneous catalyst. Catalysis Communications 59, 216-221 (2015).

106 Gholap, S. \& Gunjal, N. Thiamine hydrochloride (Vit-B1): An optimized green alternative for the synthesis of polyhydroquinoline derivatives. Iranian Journal of Catalysis 6, 147-152 (2016).

107 Waghmare, A. S., Patil, T., Kadam, K. \& Pandit, S. S. SFHS: Reusable catalyst for the synthesis of polyhydroquinoline derivatives and its molecular docking studies against tyrosine protein kinase. Iranian Journal of Catalysis 5, 1-8 (2015).

108 Surasani, R., Kalita, D., Rao, A. D., Yarbagi, K. \& Chandrasekhar, K. FeF3 as a novel catalyst for the synthesis of polyhydroquinoline derivatives via unsymmetrical Hantzsch reaction. Journal of Fluorine Chemistry 135, 91-96 (2012).

109 Kulkarni, P. Al2 (SO4) 3 is an efficient and mild acid catalyst for the one-pot, four-component synthesis of polyhydroquinoline. Journal of the Chilean Chemical Society 59, 2319-2321 (2014). 


\section{Scheme}

Schemes 1 and 2 are available in the Supplemental Files section

\section{Tables}

Due to technical limitations, tables 1 to 4 are only available as a download in the Supplemental Files section.

Figures

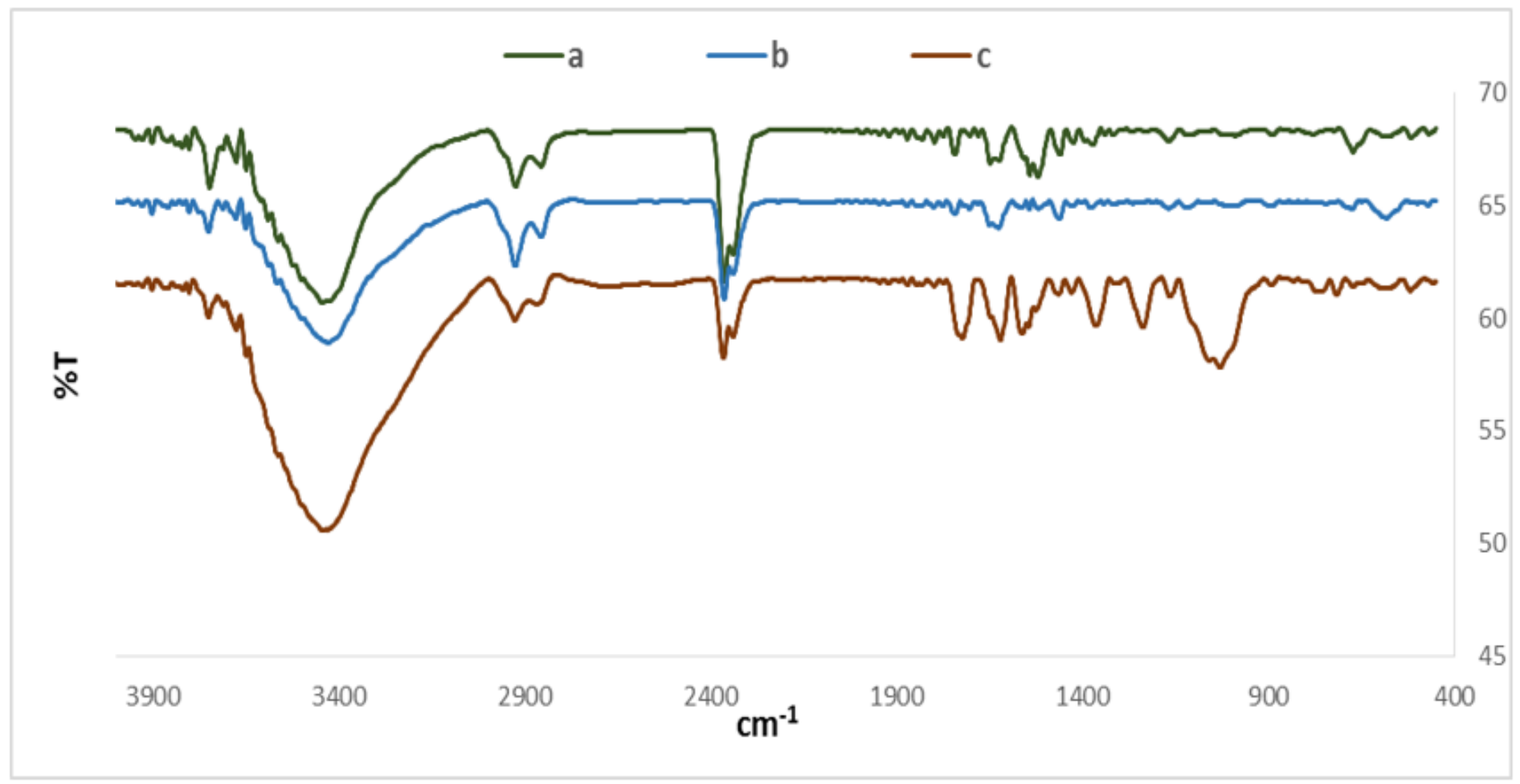

Figure 1

FTIR spectra of the commercial chitosan (a), chitosan containing epichlorohidrin linker (Cs/ECH, b) and the Cs/ECH-TMA material $(1, \mathrm{c})$. 

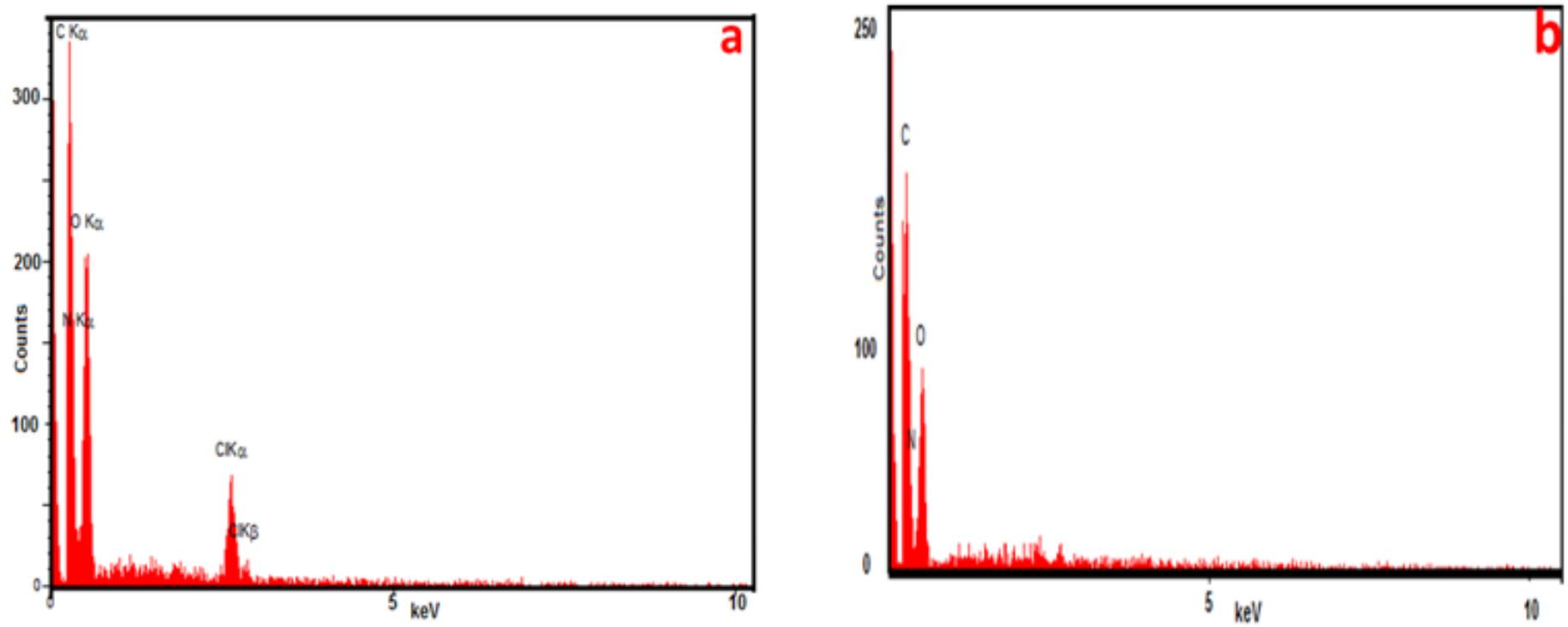

Figure 2

Energy dispersive spectroscopy (EDX) analysis of the Cs/ECH (a) and the Cs/ECH-TMA material $(1, \mathrm{~b})$.
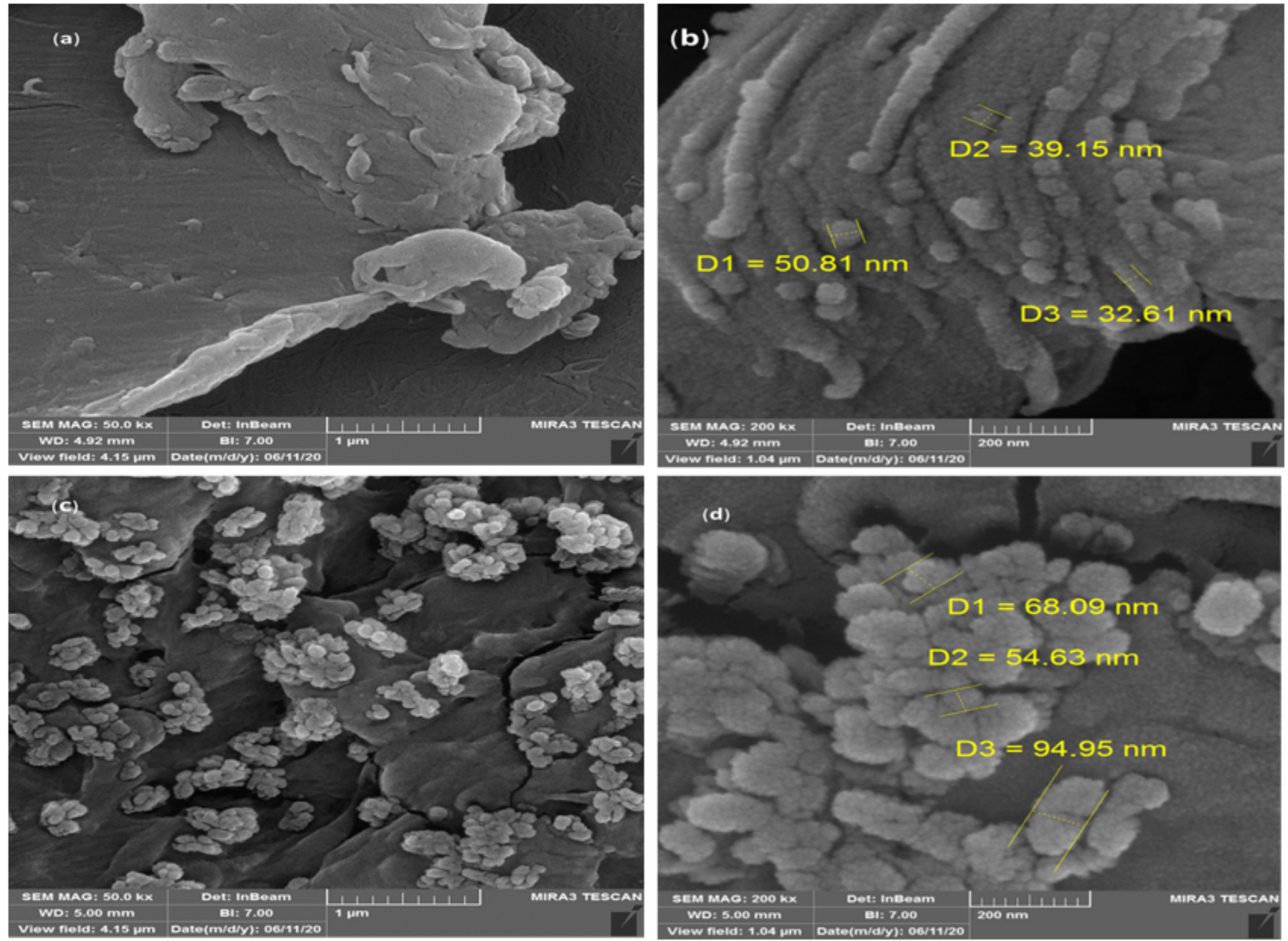

Figure 3 
FESEM images of the commercial chitosan (a-b) and the Cs/ECH-TMA (1) material (c-d).
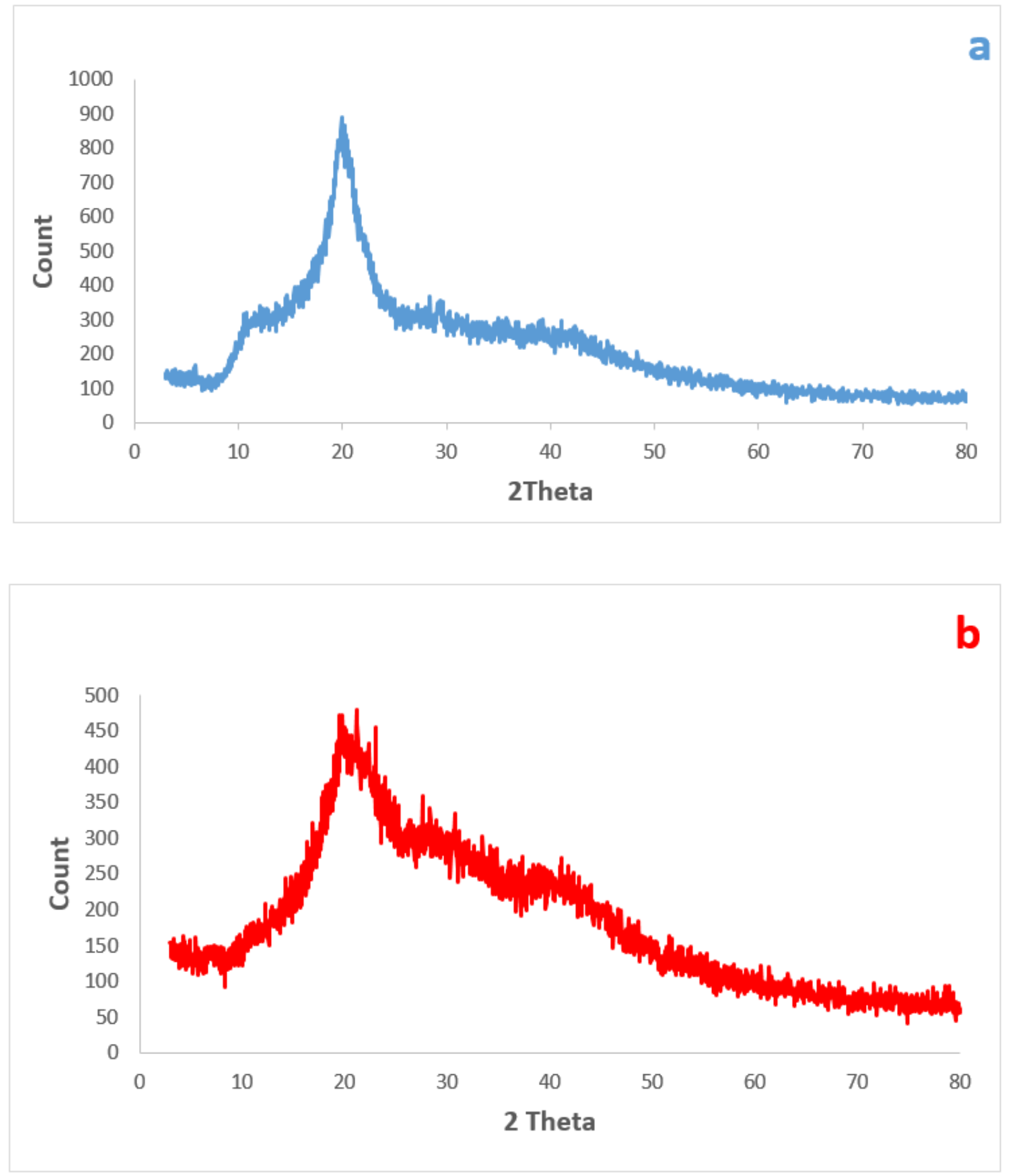

Figure 4

XRD pattern of the commercial chitosan (a) and the Cs/ECH-TMA material $(1, b)$. 


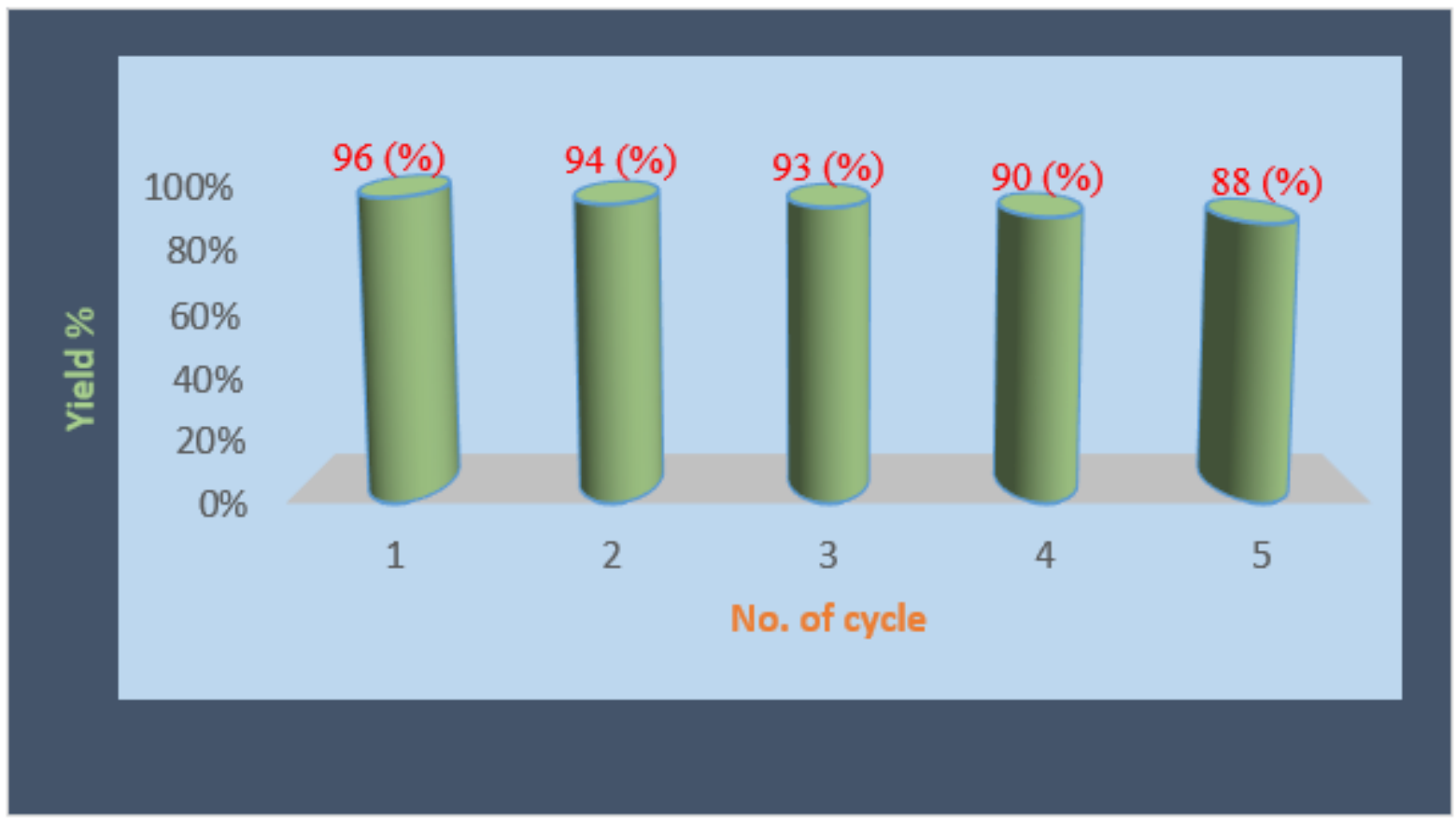

Figure 5

Reusability of the Cs/ECH-TMA catalyst (1) for synthesis of PHQ derivative 6a from 4chlorobenzaldehyde (2a), dimedone (3), ethyl acetoacetate (4) and $\mathrm{NH} 4 \mathrm{OAc}(5)$.

\section{Supplementary Files}

This is a list of supplementary files associated with this preprint. Click to download.

- Scheme1.png

- Scheme2.png

- Tables.docx 